Research Article

\title{
Evaluation of Clinical and Radiographic Findings among Patients with Traumatic Dental Injuries Seeking Delayed Treatment
}

\author{
Sanjeeb Chaudhary $\mathbb{D}^{1},{ }^{1}$ Harender Singh ${ }^{D},{ }^{2}$ Archana Gharti ${ }^{D},{ }^{3}$ and Bhawana Adhikari ${ }^{4}{ }^{4}$ \\ ${ }^{1}$ Department of Conservative Dentistry and Endodontics, School of Dental Sciences, Chitwan Medical College, Bharatpur-10, \\ Chitwan, Nepal \\ ${ }^{2}$ Department of Public Health Dentistry, School of Dental Sciences, Chitwan Medical College, Bharatpur-10, Chitwan, Nepal \\ ${ }^{3}$ Department of Conservative Dentistry and Endodontics, People's Dental College and Hospital, Kathmandu, Nepal \\ ${ }^{4}$ Department of Conservative Dentistry and Endodontics, KIST Medical College, Lalitpur, Nepal
}

Correspondence should be addressed to Sanjeeb Chaudhary; sanjeebchaudhary@gmail.com

Received 1 June 2021; Revised 9 August 2021; Accepted 18 August 2021; Published 23 August 2021

Academic Editor: Luca Testarelli

Copyright (c) 2021 Sanjeeb Chaudhary et al. This is an open access article distributed under the Creative Commons Attribution License, which permits unrestricted use, distribution, and reproduction in any medium, provided the original work is properly cited.

\begin{abstract}
Background. Time elapsed between trauma and treatment greatly influences the prognosis of traumatic dental injuries (TDIs). The aim of this study was to analyze clinical and radiographic findings related to complications of TDIs among patients seeking delayed treatment of such injuries. Materials and Methods. 123 permanent teeth with a history of previous TDIs were included in the study. Clinical findings analyzed were the type of fracture, type and number of injured teeth, crown discoloration, and pulpal status of the injured tooth (pulpal diagnosis). The radiographic findings analyzed included pulp canal obliteration (PCO), root resorption (RR), and periapical radiolucency (PR). Statistical analysis included descriptive analysis. Results. Tooth discoloration was the most common presenting complaint (53.65\%), while fall (48.78\%) was the most frequent cause of trauma. The range of time duration between trauma and presentation for treatment was 5 months to 30 years (average time 12.82 years). Pulp necrosis (PN) was the most common complication $(90.24 \%)$. Almost half of the teeth with PN had fracture injury and discoloration along with a high frequency of PR (78.37\%). Even teeth with a normal appearance were found to have a high incidence of PN (76.92\%) and PR (53.84\%). The crown discoloration was the second most frequent finding (48.78\%). Many teeth (41.66\%) with vital pulp were also discolored. Most of the teeth (79.31\%) with yellowish discoloration and all teeth with brownish discoloration were nonvital. A high frequency of PN (90\%) and PR (78.33\%) was found in teeth with discoloration. PR was the most common radiographic finding (69.10\%), while PCO and RR were observed in $17.88 \%$ and $21.13 \%$ of teeth, respectively. Conclusion. The findings of this study support the fact that delayed treatment of TDIs leads to increased complications. PN was the most common complication followed by tooth discoloration, RR, and PCO among patients seeking delayed treatment after TDIs.
\end{abstract}

\section{Introduction}

Traumatic dental injuries (TDIs) are one of the most common causes of tooth loss and hence are a well-known public dental health problem. The main objective of the treatment of TDIs is the healing of the dental pulp and periradicular tissues [1].

Time elapsed between trauma and treatment is an important factor that greatly influences the prognosis of TDIs
[2-5]. Similarly, treatment options and outcomes of treatment of traumatized teeth are significantly affected by the time duration between injury and the start of treatment. Treatment provided immediately after trauma has a significant effect on the prognosis of an injured tooth [5-7]. Timely treatment of an injured tooth is important for ensuring a favorable outcome and improving prognosis $[5,8,9]$. Immediate treatment of the traumatized tooth is the most important factor for preserving pulp vitality and for reducing complications $[3,6,10]$. 
Delayed treatment of TDIs has an unfavorable effect on the prognosis of injured teeth, which can cause loss of pulp vitality and thus poor prognosis $[6,8,10,11]$. Treatment of TDIs is always aimed towards the reduction of complications. Delayed treatment is one of the factors linked with an increased rate of complications in teeth with TDIs [12, 13]. Delayed treatment of a traumatized tooth increases the risk of complications [5, 8, 11]. Even uncomplicated crown fractures can lead to various complications as a result of delayed treatment $[3,14]$.

However, treatment of TDIs is frequently neglected or delayed, which leads to various complications $[5,8]$. Treatment of TDIs is time-consuming and expensive, and most of these injuries remain asymptomatic for a long time. Therefore, they are frequently ignored and left untreated $[15,16]$. As a result, a low rate of treatment of TDIs is observed worldwide $[4,16]$. Patients with TDIs come for treatment only after the appearance of symptoms or complications [5]. The development of these complications frequently leads to late presentation for treatment [13].

Although healing of dental pulp and adjacent tissue is the most favorable outcome of TDIs, complications such as pulp necrosis (PN), infection of the root canal system, pulp canal obliteration (PCO), crown discoloration, root resorption (RR), bone resorption, and ankylosis have frequently been associated with TDIs [1,4]. These pulpal and periodontal complications related to TDIs can present early or even after several months or years of injury [3]. Recently, the use of magnetic resonance imaging (MRI) has been found to have an important application in the diagnosis, treatment, prognosis, and follow-up of these periapical bone lesions [17].

Therefore, the aim of this study was to analyze clinical and radiographic findings related to complications of TDIs among patients seeking delayed treatment of such injuries.

\section{Materials and Methods}

This study was conducted at the Department of Conservative Dentistry and Endodontics, School of Dental Sciences, Chitwan Medical College, Nepal, between January 2018 and December 2019, for a period of two years. It included patients coming for delayed treatment of teeth with a previous history of TDIs to permanent dentition. Informed consent was taken according to ethical principles. This study was approved by the Institutional Review Board of the Chitwan Medical College (Ethical Clearance No.: CMC-IRC/076/ 077-148).

A total of 123 permanent teeth with a previous history of TDIs were evaluated in this study. The study included 82 patients comprising 47 males (57.31\%) and 35 females $(42.68 \%)$. The ratio between male and female is $1.34: 1$. The age of the patient ranged from 14 to 53 years (mean age was 28.03 years).

A thorough clinical and radiographic examination was conducted using a digital intraoral periapical radiograph (Carestream Health Inc) exposed with a paralleling technique and an exposure time 0.125 seconds at $60 \mathrm{kV}$ and $7 \mathrm{~mA}$. The patient's name, age, gender, chief complaint (reason for seeking treatment), time elapsed between trauma and presentation for treatment, and the etiology of trauma were investigated.

Findings from the clinical examination and tests, as well as radiographic examination, were documented. The clinical findings analyzed were type of fracture injury, type and number of injured teeth, crown discoloration, intraoral sinus, swelling, and pulpal status of the injured tooth (pulpal diagnosis). The radiographic findings analyzed were PCO, $\mathrm{RR}$, and periapical radiolucency $(\mathrm{PR})$.

The diagnosis of $\mathrm{PN}$ was made based on clinical and radiological findings. The tooth was diagnosed as $\mathrm{PN}$ when clinical findings (pain, swelling, crown discoloration, negative response to EPT, tenderness to percussion, and presence of sinus) were observed along with radiographic findings (PR and or RR) [18]. PCO and RR were diagnosed based on radiographic analysis. Diagnosis of PCO and RR was based on radiographic analysis. Radiographic analysis was done separately by two endodontists using the RadioVisioGraphy (RVG) imaging system, Dental Imaging Software, 6.14.4 (Carestream Health Inc. 2014).

Teeth with a previous history of treatment were excluded from the study. Similarly, teeth without a previous history of TDIs were also excluded from the study.

The data collected were subjected to descriptive analysis and chi-square tests were applied for association analysis. Statistical analysis of the obtained data was performed using Statistical Package for the Social Sciences (SPSS, version 22.0 (IBM SPSS)). The level of significance was set at 5\%.

\section{Results}

The most frequently observed history of TDIs was in the age group 14-20, followed by the age group 21-25. Comparison of the frequency of TDIs between genders and age groups found no significant difference $(p>0.05)$. The distribution of TDIs with respect to age groups, gender, and etiology is shown in Table 1. Fall (48.78\%) was the most frequent cause of trauma, followed by impact injury (20.04\%). Similarly, the comparison of the frequency of the causes between the genders and differences between the cause of trauma and age distribution was also not statistically significant $(p>0.05)$.

The most commonly traumatized tooth was the maxillary right central incisor (36.58\%), followed by the maxillary left central incisor (23.57\%). Maxillary teeth (74\%) were more frequently involved than mandibular teeth $(26 \%)$. The distribution of the affected tooth type is presented in Table 2. Tooth distribution, according to clinical and radiographic findings, is shown in Table 3. The most common presenting complaint was tooth discoloration $(44 ; 53.65 \%)$ followed by swelling $(22 ; 26.82 \%)$, pus discharge $(14 ; 17.07 \%)$, and pain $(2 ; 2.43 \%)$. The swelling was found in association to 14 teeth, whereas intraoral sinus was seen in relation to 13 teeth. Similarly, swelling associated with intraoral sinus was observed in 5 teeth.

The range of time duration between trauma and presentation for treatment was 5 months to 30 years. The average time of presentation after trauma was 12.82 years 
TABLE 1: Distribution of age, gender, and etiology.

\begin{tabular}{lccc}
\hline Age distribution & No. $(\%)$ & M:F (no.) & Fall: impact: RTA: sports: assault \\
\hline $14-20$ & $20(24.39 \%)$ & $12: 8$ & $12: 5: 3: 0: 0$ \\
$21-25$ & $19(23.17 \%)$ & $11: 8$ & $10: 4: 2: 2: 1$ \\
$26-30$ & $17(20.73 \%)$ & $11: 6$ & $6: 7: 1: 3: 0$ \\
$31-35$ & $8(9.75 \%)$ & $4: 4$ & $5: 3: 0: 0: 0$ \\
$36-40$ & $8(9.75 \%)$ & $4: 4$ & $2: 1: 4: 1: 0$ \\
$41-45$ & $5(6.09 \%)$ & $2: 3$ & $3: 2: 0: 0: 0$ \\
$46-50$ & $3(3.65 \%)$ & $2: 1$ & $2: 1: 0: 0: 0$ \\
$51-55$ & $2(2.4 \%)$ & $1: 1$ & $0: 0: 2: 0: 0$ \\
Total & 82 & $47: 35$ & $40: 23: 12: 6: 1$ \\
\hline
\end{tabular}

TABLE 2: Distribution of dental trauma according to affected tooth type.

\begin{tabular}{llllllll}
\hline \multicolumn{1}{l}{ Type of injured tooth: number } \\
\hline Incisors (120) & $11=45$ & $12=11$ & $21=29$ & $22=4$ & $31=9$ & $32=7$ & $41=10$ \\
Canines (3) & $13=1$ & $23=1$ & $33=$ nil & $43=1$ & & $42=5$ \\
\hline
\end{tabular}

Teeth numbering, according to the FDI numbering system.

TABLE 3: Tooth distribution according to clinical and radiographic findings.

\begin{tabular}{|c|c|c|c|c|c|c|c|c|c|c|c|c|}
\hline Tooth & 13 & 12 & 11 & 21 & 22 & 23 & 32 & 31 & 41 & 42 & 43 & Total \\
\hline Vital pulp & & & 5 & 6 & 1 & & & & & & & 12 \\
\hline Pulp necrosis & 1 & 11 & 40 & 23 & 3 & 1 & 7 & 9 & 10 & 5 & 1 & 111 \\
\hline Normal appearance (NA) & & 1 & 7 & 2 & 2 & & 4 & 3 & 2 & 4 & 1 & 26 \\
\hline Enamel fracture $(\mathrm{E} \#)$ & & & 6 & 2 & 1 & & & & 1 & & & 10 \\
\hline Enamel dentin fracture (ED\#) & 1 & 5 & 15 & 8 & & 1 & & 2 & & & & 32 \\
\hline Complicated crown fracture (EDP\#) & & 2 & 4 & 1 & & & 2 & 2 & & & & 11 \\
\hline Brownish discoloration (BD) & & 1 & 13 & 11 & & & & 3 & 2 & 1 & & 31 \\
\hline Yellowish discoloration (YD) & 1 & 2 & 14 & 8 & & 1 & 1 & & 2 & & & 29 \\
\hline Normal radiographic findings (NRF) & & 1 & 6 & 5 & 1 & & 1 & 1 & & 1 & & 16 \\
\hline Periapical radiolucency $(\mathrm{PR})$ & 1 & 9 & 27 & 19 & 2 & 1 & 5 & 7 & 9 & 4 & 1 & 85 \\
\hline Pulp canal obliteration (PCO) & & 1 & 11 & 6 & 2 & & & & & 2 & & 22 \\
\hline Root resorption (RR) & & 2 & 13 & 7 & 3 & & & & 1 & & & 26 \\
\hline
\end{tabular}

(within a year $=3(3.65 \%), 2-4$ years $=16(19.51 \%), 5-7$ years $=13 \quad(15.85 \%), \quad 8-10 \quad$ years $=15 \quad(18.29 \%), \quad 11-15$ years $=21(25.60 \%), 16-20$ years $=6(7.31 \%), 21-25$ years $=4$ $(4.87 \%)$, and $26-30$ years $=4(4.87 \%))$.

Vital pulp was detected in $(9.75 \%)$ teeth upon diagnosis. Among them, $33.33 \%$ of teeth had a fracture, whereas $41.66 \%$ of teeth had discoloration. Similarly, on radiographic examination and $50 \%$ of teeth had PCO, and $16.66 \%$ of teeth had RR. Similarly, nonvital pulp (PN) was diagnosed in $90.24 \%$ of teeth. Among them, $44.14 \%$ of teeth had a fracture, and $49.54 \%$ of teeth were discolored. Likewise, $78.37 \%$ of teeth were associated with PR, $13.51 \%$ of teeth had PCO, and $20.72 \%$ had RR on radiographic evaluation. The tooth distribution, clinical and radiographic findings associated with pulpal diagnosis are shown in Table 4.

Likewise, on clinical examination, $21.13 \%$ of teeth had a normal appearance (NA). Among them, $76.92 \%$ of teeth were diagnosed as having PN. 53.84\% of teeth were related to PR, 38.46\% of teeth had PCO, and $19.23 \%$ had RR on radiographic findings. Enamel fracture (E\#) was seen in $8.13 \%$ of teeth, of which $90 \%$ of teeth had PN. PR was found in $90 \%$ of teeth, while $10 \%$ had PCO and $50 \%$ had RR. Enamel dentin fracture (ED\#) was observed in $26.01 \%$ of teeth. Among them, $84.37 \%$ teeth were diagnosed to have PN. Also $75 \%$ teeth had PR, and $28.12 \%$ of teeth were associated with RR. Similarly, all teeth with complicated crown fractures were diagnosed with PN. Among them, $72.72 \%$ of teeth were linked to PR on radiographic examination.

Tooth discoloration was a frequent finding $(48.78 \%)$ in this study. Among them, $48.33 \%$ of teeth had yellowish discoloration. $79.31 \%$ of teeth with yellowish discoloration had PN. Also, $68.96 \%$ of teeth were associated with PR and $27.58 \%$ of teeth had PCO and $31.03 \%$ had RR. All teeth with brownish discoloration (51.66\%) were nonvital. $87.09 \%$ of teeth with brownish discoloration had PR, while only $3.22 \%$ of them had PCO and RR $16.12 \%$. Overall, a high incidence of PN $(54 ; 90 \%)$ and PR $(78.33 \%)$ was found in teeth with discoloration. However, the frequency of RR $(23.33 \%)$ and PCO (15\%) observed was low in teeth with discoloration. The tooth distribution, pulpal diagnosis, and clinical and radiographic findings related to clinical examination are shown in Table 5.

Upon analysis of radiographs, $13 \%$ of teeth had normal radiographic findings (NRF). Among them (25\%) were 
TABLE 4: Distribution of pulpal diagnosis.

\begin{tabular}{|c|c|c|c|c|}
\hline Diagnosis & Patient & Teeth & Clinical findings & Radiographic findings \\
\hline Vital pulp & 9 & $12(9.75 \%)$ & $\begin{array}{c}(\mathrm{NA}=4, \#=3, D=4 \\
\#+D=1)\end{array}$ & $\mathrm{NRF}=6, \mathrm{PCO}=4, \mathrm{PCO}+\mathrm{RR}=2$ \\
\hline $\begin{array}{l}\text { Pulp } \\
\text { necrosis }\end{array}$ & 73 & $\begin{array}{c}111 \\
(90.24 \%)\end{array}$ & $\begin{aligned} &(\mathrm{NA}=29, \#=27, D=33 \\
&\#+D=22)\end{aligned}$ & $\begin{aligned} \mathrm{NRF}=14, \mathrm{PR}= & 64, \mathrm{PCO}=5, \mathrm{RR}=2, \mathrm{PR}+\mathrm{PCO}=5, \mathrm{PR}+\mathrm{RR}=16, \\
& \mathrm{PCO}+\mathrm{RR}=3, \mathrm{PR}+\mathrm{PCO}+\mathrm{RR}=2\end{aligned}$ \\
\hline
\end{tabular}

\# = crown fracture; $D=$ crown discoloration.

TABLE 5: Distribution of clinical findings.

\begin{tabular}{|c|c|c|c|c|c|}
\hline $\begin{array}{l}\text { Clinical } \\
\text { findings }\end{array}$ & $\begin{array}{l}\text { Number of } \\
\text { patients }\end{array}$ & $\begin{array}{c}\text { Number of } \\
\text { teeth }\end{array}$ & Clinical findings & Diagnosis & Radiographic findings \\
\hline $\begin{array}{l}\text { Normal } \\
\text { appearance }\end{array}$ & 21 & $26(21.13 \%)$ & Normal appearance & $\begin{array}{l}(\mathrm{NP}=6 ; 23.07 \% \\
\mathrm{PN}=20 ; 76.92 \%)\end{array}$ & $\begin{array}{c}\mathrm{NRF}=3, \mathrm{PR}=12, \mathrm{PCO}=5, \mathrm{PR}+\mathrm{PCO}=1 \\
\mathrm{PCO}+\mathrm{RR}=4, \mathrm{PR}+\mathrm{RR}=1\end{array}$ \\
\hline E\# & 10 & $10(8.13 \%)$ & $(\mathrm{E} \#=5, \mathrm{E} \#+D=5)$ & $\begin{array}{l}(\mathrm{NP}=1 ; 10 \% \\
\mathrm{PN}=9 ; 90 \%)\end{array}$ & $\begin{array}{c}\mathrm{NRF}=1, \mathrm{PR}=4, \mathrm{PR}+\mathrm{RR}=4 \\
\mathrm{PR}+\mathrm{PCO}+\mathrm{RR}=1\end{array}$ \\
\hline ED\# & 25 & $32(26.01 \%)$ & $\begin{array}{c}(\mathrm{ED} \#=16 \\
\mathrm{ED} \#+D=16)\end{array}$ & $\begin{array}{l}(\mathrm{NP}=5 ; 15.62 \% \\
\mathrm{PN}=27 ; 84.37 \%)\end{array}$ & $\mathrm{NRF}=7, \mathrm{PR}=16, \mathrm{PR}+\mathrm{RR}=8, \mathrm{RR}=1$ \\
\hline EDP\# & 9 & $11(8.94 \%)$ & $\begin{array}{c}(\mathrm{EDP} \#=9 \\
\mathrm{EDP} \#+D=2)\end{array}$ & $(\mathrm{PN}=11 ; 100 \%)$ & $\mathrm{NRF}=3, \mathrm{PR}=8$ \\
\hline $\mathrm{BD}$ & 27 & $31(51.66 \%)$ & $\begin{array}{c}(D=19, \mathrm{ED} \#+D=10 \\
\mathrm{EDP} \#+D=2)\end{array}$ & $(\mathrm{PN}=31 ; 100 \%)$ & $\begin{array}{c}\mathrm{NRF}=3, \mathrm{PR}=22, \mathrm{PR}+\mathrm{PCO}=1, \mathrm{PR}+\mathrm{RR}=4, \\
\mathrm{RR}=1\end{array}$ \\
\hline YD & 27 & $29(48.33 \%)$ & $\begin{array}{l}(D=18, \mathrm{E} \#+D=5 \\
\mathrm{ED} \#+D=6)\end{array}$ & $\begin{array}{l}(\mathrm{NP}=6 ; 20.68 \% \\
\mathrm{PN}=23 ; 79.31 \%)\end{array}$ & $\begin{array}{c}\mathrm{NRF}=3, \mathrm{PR}=11, \mathrm{PCO}=4, \mathrm{PR}+\mathrm{PCO}=2 \\
\mathrm{PR}+\mathrm{RR}=6, \mathrm{RR}=1, \mathrm{PCO}+\mathrm{RR}=1 \\
\mathrm{PR}+\mathrm{PCO}+\mathrm{RR}=1\end{array}$ \\
\hline
\end{tabular}

discolored, whereas (56.25\%) had fracture injuries. Also, $50 \%$ of teeth with NRF were nonvital.

PR (69.10\%) was the most common radiographic finding. $52.94 \%$ of teeth had discoloration, and $48.23 \%$ of teeth had fracture injury among the teeth with PR. All teeth with PR were nonvital, while $22.35 \%$ teeth had RR and $8.23 \%$ teeth had PCO.

PCO was detected in $17.88 \%$ of teeth. Among them, half were discolored. The yellowish discoloration was found in $72.72 \%$ of teeth, whereas only $27.27 \%$ of teeth had brownish discoloration. Also, $63.63 \%$ of teeth with PCO were nonvital. On radiographic examination, $31.81 \%$ of teeth were associated with $\mathrm{PR}$ and $27.27 \%$ of teeth had RR in teeth with PCO.

Likewise, $21.13 \%$ of teeth were found to have RR on radiographic evaluation. Among them, $88.46 \%$ of teeth had $\mathrm{PN}, 50 \%$ of teeth were discolored, while $73.07 \%$ of teeth had PR and $26.92 \%$ of teeth had PCO. The tooth distribution, pulpal diagnosis, and clinical and radiographic findings according to radiographic examination are shown in Table 6.

\section{Discussion}

Immediate treatment after dental trauma significantly improves the prognosis of the injured tooth and is equally important for preventing and reducing complications. Late presentation for treatment after TDIs was identified as the reason for higher frequency of complications in a recent study [13]. Timely treatment of TDIs also helps in better management of posttraumatic complications [19]. The time interval between injury and presentation for treatment ranged between 5 months and 30 years in this study.
Many patients with TDIs do not seek treatment as long as it remains asymptomatic [20]. Tooth discoloration (53.65\%) was the most common presenting complaint, followed by swelling in this study. This indicates that several patients, unless esthetically concerned or presence of pain and discomfort, do not come for treatment of TDIs.

Patients generally seek immediate treatment for severe injuries due to road traffic accidents, assaults, or sports. However, traumas due to impact and fall injury are considered mild injuries and are often neglected since they are seldom severe or symptomatic. Hence, patients tend to delay or ignore treatment for these kinds of injuries. This may explain the findings of this study, where fall (48.78\%) was the most frequent cause of trauma. Most of the TDIs were due to fall and impact injury (Table 1).

$\mathrm{PN}$ has been found to be the most frequent posttraumatic complication in all types of TDIs $[5,14,21]$. Depending on the severity of TDIs the prevalence of PN ranges from $17-100 \%$. In a recent study, PN was the most common complication among patients with late presentation for treatment [13]. Similar results were found in the present study. PN was the most frequent complication, with 90.24\% of teeth diagnosed with PN. Almost half of the teeth with $\mathrm{PN}$ had fracture injury and discoloration. Also, a high frequency of PR (78.37\%) was seen in teeth with PN. However, the rate of PCO and RR was low (Table 4). Nevertheless, some studies have reported a lower frequency of PN. A similar prevalence of PN (26.9\%) was reported in a study by Hecova et al. and Kallel et al., while Lin et al. reported a prevalence of $\mathrm{PN}$ at $(34.2 \%)[5,14,21]$.

The prevalence of PN is very low in enamel-fractured and dentin-fractured teeth without an associated luxation 
TABLE 6: Distribution of radiographic findings.

\begin{tabular}{|c|c|c|c|c|c|}
\hline & $\begin{array}{c}\text { Number of } \\
\text { patient }\end{array}$ & $\begin{array}{c}\text { Number of } \\
\text { teeth }\end{array}$ & Clinical findings & Diagnosis & Radiographic findings \\
\hline $\begin{array}{l}\text { Normal } \\
\text { radiographic } \\
\text { findings (NRF) }\end{array}$ & 14 & $16(13 \%)$ & $\begin{array}{c}(\mathrm{NA}=5, \mathrm{E} \#=1, \mathrm{ED} \#=4, \mathrm{EDP} \#=2, \\
D=2, \mathrm{ED} \#+D=2)\end{array}$ & $\begin{array}{l}(\mathrm{NP}=8 ; 50 \% \\
\mathrm{PN}=8 ; 50 \%)\end{array}$ & NRF \\
\hline $\begin{array}{l}\text { Periapical } \\
\text { radiolucency }(\mathrm{PR})\end{array}$ & 65 & $\begin{array}{c}85 \\
(69.10 \%)\end{array}$ & $\begin{array}{l}(\mathrm{NA}=17, \mathrm{E} \#=4, \mathrm{ED} \#=12, \\
\mathrm{EDP} \#=7, D=27, \mathrm{E} \#+D=5 \\
\mathrm{ED} \#+D=12, \mathrm{EDP} \#+D=1)\end{array}$ & $(\mathrm{PN}=85 ; 100 \%)$ & $\begin{array}{c}\mathrm{PR}=61, \mathrm{PR}+\mathrm{PCO}=5 \\
\mathrm{PR}+\mathrm{RR}=17 \\
\mathrm{PR}+\mathrm{PCO}+\mathrm{RR}=2\end{array}$ \\
\hline $\begin{array}{l}\text { Pulp canal } \\
\text { obliteration (PCO) }\end{array}$ & 20 & $\begin{array}{c}22 \\
(17.88 \%)\end{array}$ & $(\mathrm{NA}=11, D=10, \mathrm{E} \#+D=1)$ & $\begin{array}{l}(\mathrm{NP}=8 ; 36.36 \% \\
\mathrm{PN}=14 ; 63.63 \%)\end{array}$ & $\begin{array}{c}\mathrm{PCO}=10, \mathrm{PCO}+\mathrm{PR}=6 \\
\mathrm{PCO}+\mathrm{RR}=5 \\
\mathrm{PCO}+\mathrm{PR}+\mathrm{RR}=1\end{array}$ \\
\hline $\begin{array}{l}\text { Root resorption } \\
(\mathrm{RR})\end{array}$ & 21 & $26(21.13 \%)$ & $\begin{array}{c}(\mathrm{NA}=6, \mathrm{E} \#=1, \mathrm{ED} \#=6, \\
\mathrm{E} \#+D=4, \mathrm{ED} \#+D=3, D=6)\end{array}$ & $\begin{array}{l}(\mathrm{NP}=3 ; 11.53 \% \\
\mathrm{PN}=23 ; 88.46 \%)\end{array}$ & $\begin{array}{c}\mathrm{RR}=2, \mathrm{RR}+\mathrm{PR}=17 \\
\mathrm{RR}+\mathrm{PCO}=5 \\
\mathrm{RR}+\mathrm{PR}+\mathrm{PCO}=2\end{array}$ \\
\hline
\end{tabular}

\# = crown fracture; $D=$ crown discoloration.

injury. However, the risk of PN is higher in teeth with dentin fracture compared to teeth with enamel fracture $[2,3,18,22]$. The incidence of PN in enamel and dentinfractured teeth in a recent study was $4 \%$ and $22 \%$, respectively [18]. Most of the complications were found in teeth with enamel-dentine fracture $(93.4 \%)$, followed by concussion injury (55.6\%) in another recent study among patients coming for late treatment of TDIs [13]. Although crown fracture has a low risk of $\mathrm{PN}$ when proper treatment is provided, $\mathrm{PN}$ as a result of crown fracture was reported by Robertson et al. to be more common [3]. A high rate of PN (88.67\%) and PR (77.35\%) was found in teeth with fracture injury. 90\% teeth with E\# and $84.37 \%$ teeth with ED\# were nonvital, whereas all teeth with complicated crown fracture were nonvital in this study (Table 5). This suggests that even teeth with uncomplicated fractures can lead to a rise in complications due to delayed treatment.

$\mathrm{PN}$ in uncomplicated crown fractures is rare and ranges between $2 \%$ and $5 \%$. However, $\mathrm{PN}$ is very common in fractured teeth without treatment. Since complications can arise from the invasion of bacteria into the dentinal tubules, an increased PN is found even in the absence of luxation injuries, particularly in teeth with delayed treatment $[9,22,23]$.

PN was also a common finding in fractured teeth among patients seeking delayed treatment in another previous study [24]. Therefore, protection of the exposed dentin should be done as soon as possible. Similarly, immediate sealing of the exposed pulp is also essential for a favorable prognosis [7]. Even teeth with NA were found to have a high rate of PN (76.92\%) and PR (53.84\%) in this study. Similarly, half of the teeth with NRF were also nonvital.

$\mathrm{PN}, \mathrm{PCO}, \mathrm{RR}$, and ankylosis are important complications linked to luxation injures. Luxation injuries due to the damage to the neurovascular bundle are associated with a higher incidence of PN [18]. Many studies have found PN to be the most common complication in teeth with luxation injury $[8,25]$. The development of $\mathrm{PN}$ after luxation injuries is related to several significant clinical factors such as stage of root development, type, and extent of luxation injury, type of treatment, and delayed initial treatment [26-29]. Teeth with complete root development have a high risk of developing PN $[14,18,26]$. PN is especially more common in teeth with luxation injury having mature apex $[30,31]$. In a retrospective study, teeth with completed root development demonstrated a higher prevalence of PN in all types of luxation injuries [14]. All of the teeth evaluated in this study had complete root development, which could be the reason for a high incidence of PN observed.

Concussion and subluxation injuries have a low risk of $\mathrm{PN}$, whereas lateral luxation and intrusion have a high rate of PN [8, 14, 31-33]. Various studies have also found a high incidence of $\mathrm{PN}$ in teeth with concomitant fracture and luxation injury [3, 27-29]. A study found an increased risk of $\mathrm{PN}$ in crown fractured teeth with an associated concussion, subluxation, extrusion, lateral luxation, and intrusion injury in ascending order [18].

Time period of development of PN after dental trauma varies depending on the type of injury. Although most of the PN developed within 12 months of trauma, the incidence of PN within 3 months was significantly higher in a study [18]. Therefore, the first 3 months after TDIs are very important with respect to monitoring and follow-up [18]. Similarly, most of the PN was detected within the first six months after trauma in other studies $[9,22,34]$. However, it is agreed that PN mostly occurs within the first year after trauma $[14,21]$. PN was observed as early as 5 months after trauma in the present study. Therefore, frequent follow up is essential for early detection and treatment of complications. Hence, a follow-up period of more than one year is recommended for the evaluation of pulpal healing.

PCO is a pulpal healing complication commonly found in teeth with luxation injuries, root fracture, and reimplanted teeth $[13,24,35,36]$. The prevalence of PCO after TDIs has been found to range from $3.7 \%$ to $40 \%[21,35,37]$. In this study, $17.88 \%$ of the teeth were diagnosed with PCO (Table 6). According to Bastos and Cortes, teeth with extrusive and lateral luxation injury demonstrate the highest frequency of PCO which is also supported by other studies $[8,30,31,35,38]$. The incidence of PCO is significantly associated with the degree of displacement and to the degree of root development $[3,30]$. PCO is also considerably more 
frequent in teeth with incomplete root development [26]. PCO can be detected clinically 3 months after trauma [37].

Although very rare, $\mathrm{PN}$ can occur in teeth with PCO. PN is a late complication associated with $\mathrm{PCO}$ and ranges from $1 \%$ to $16 \%$ [35, 37]. However, a high frequency of PN (63.63\%) was observed in teeth with PCO in the present study. Most of the teeth with PCO were nonvital. PN in teeth with PCO has been significantly related to the severity of the injury and the stage of root development [35]. All of the teeth with PN and PCO in this study had complete root development.

Teeth with PCO generally have discoloration, which is clinically seen as a yellowish discoloration of the crown [24]. Yellowish discoloration in teeth with PCO is a frequent finding ranging from $8.3 \%$ to $79 \%$. In contrast, brownish discoloration is very rare (1\%) in teeth with PCO [35]. A study detected yellowish discoloration in $67.4 \%$ and brownish discoloration in $12.3 \%$ of teeth with PCO. Similarly, $33.3 \%$ of teeth with PCO had periapical lesions, while $30.7 \%$ of teeth had NRF [39]. In this study, half of the teeth with PCO were discolored. Yellowish discoloration (72.72\%) was more common than brownish discoloration (27.27\%). However, the frequency of PR and RR was low (Table 6). Interestingly, PCO was found only in teeth with E\# in this study. This suggests that teeth with mild trauma are more likely to develop PCO.

Tooth discoloration, a long-term complication of dental trauma, is a frequent finding in a traumatized tooth. Grayish and brownish discoloration of a traumatized tooth indicates $\mathrm{PN}$, while yellowish discoloration is a sign associated with PCO. Patients with mild injuries such as concussion and subluxation usually have negligible symptoms and hence seek treatment only when it becomes symptomatic. These patients with discolored teeth often come for delayed treatment [24]. Tooth discoloration was the second most common complication observed in a study related to patient seeking delayed treatment after TDIs [13]. Similarly, crown discoloration was the second most common finding (48.78\%) in this study. $48.33 \%$ teeth had yellowish discoloration, while $51.66 \%$ teeth were of brownish discoloration (Table 5).

Upon further evaluation, most of the teeth (79.31\%) with yellowish discoloration were nonvital with a high incidence of PR (68.96\%). A very high frequency of PN was also seen in teeth with brownish discoloration. All teeth with brownish discoloration were nonvital. Most of the teeth with brownish discoloration have been associated with periapical lesions $[35,39]$. A high incidence of PR $(87.09 \%)$ in teeth with brownish discoloration was also found in this study. Overall, a high frequency of PN (90\%) and PR (78.33\%) was observed in teeth with discoloration. In contrast, the rate of RR and PCO was low. The results of this study are in contrast to a former study in which PCO was found in $79.2 \%$, and PN was found in $20.8 \%$ of discolored teeth [24]. This difference may be due to the inclusion of only discolored teeth in the previous study. Furthermore, the time duration of arrival for treatment was earlier (mean $=13.2$ months) in the previous study, whereas in the present study, the time duration for arrival for treatment was late (mean $=12.82$ years).
Additionally, many teeth (41.66\%) with vital pulp were also discolored in this study.

PR was the most common radiographic finding (69.10\%) (Table 6). Almost half of the teeth with PR had fracture injury and discoloration. All teeth with PR were nonvital. However, the incidence of PCO and RR was low. A very low frequency of periodontal complications is found after concussion and subluxation injuries $[25,40]$. In the same way, the risk of periodontal complications in teeth with extrusive luxation and lateral luxation injuries are also generally low [41].

$\mathrm{RR}$ is an important periodontal healing complication of TDIs. RR was observed in $(21.13 \%)$ of teeth with a high rate of PN (88.46\%) and PR (73.07\%). Half of the teeth with RR were also discolored (Table 6).

Surprisingly, RR was not detected in teeth with a complicated crown fracture in this study since RR is mostly associated with luxation injury. RR was more frequently associated with intrusive luxation (93\%), followed by avulsions (89\%), lateral luxation (80\%), and extrusive luxation (77\%) in a recent study [42]. This is also supported by a recent review and various studies stating RR to be mostly associated with intrusive luxation, followed by extrusive luxation, lateral luxation, subluxation, and concussion injury [30, 32, 33, 43]. Early repositioning of luxated and displaced teeth helps to prevent the onset of RR [12]. The risk of RR is likewise high in teeth with concomitant fracture and luxation injury because of the increased risk of $\mathrm{PN}$ in such teeth. $\mathrm{RR}$ is generally seen within five months from injury [21, 22]. However, the use of cone-beam computed tomography (CBCT) has been found to be superior in the early detection and diagnosis of PR and RR [44].

Other periodontal complications related to TDIs such as marginal bone loss, mobility, transient apical breakdown, and cervical-invasive resorption, however, were not evaluated in this study.

Early diagnosis of complications is very important since management of such tooth is difficult. Therefore, timely treatment and follow-up of an injured tooth, according to guidelines, are important for ensuring a favorable outcome, protecting pulp vitality, and reducing complications [34]. Similarly, the concept of torque range as proposed by a recent study can be very useful for the prevention of intracanal separation of the instrument and other iatrogenic errors during root canal preparation of a tooth with PCO [45].

Knowledge about the various consequences in teeth with TDIs can help to provide better treatment and reduce complications. Likewise, information regarding the timeline of the development of possible complications of TDIs is also essential to anticipate and prevent them.

A traumatized tooth can have multiple signs and symptoms related to complications. Information from this study may help to predict the possibility of various likely complications related to TDIs and identify these complications early. Outcomes of this study may additionally assist in monitoring and follow-up of such teeth as well. Future studies related to the management of complications of TDIs with follow-up of the patients can be conducted, which 
might be valuable in better understanding of these complications linked to TDIs.

\section{Conclusion}

The findings of this study support the fact that delayed treatment of TDIs leads to increased complications. Pulp necrosis was the most common complication followed by tooth discoloration, root resorption, and pulp canal calcification among patients seeking delayed treatment after TDIs in this study.

\section{Data Availability}

The data used to support the findings of this study are available from the corresponding author upon request.

\section{Conflicts of Interest}

The authors declare no conflicts of interest in this work.

\section{References}

[1] R. Lam, "Epidemiology and outcomes of traumatic dental injuries: a review of the literature," Australian Dental Journal, vol. 61, pp. S4-S20, 2016.

[2] I. Viduskalne and R. Care, "Analysis of the crown fractures and factors affecting pulp survival due to dental trauma," Stomatologiia, vol. 12, pp. 109-115, 2010.

[3] A. Robertson, F. M. Andreasen, J. O. Andreasen, and J. G. Norén, "Long-term prognosis of crown-fractured permanent incisors. The effect of stage of root development and associated luxation injury," International Journal of Paediatric Dentistry, vol. 10, pp. 191-199, 2000.

[4] V. Zaleckiene, V. Peciuliene, V. Brukiene, and S. Drukteinis, "Traumatic dental injuries: etiology, prevalence and possible outcomes," Stomatologiia, vol. 16, pp. 7-14, 2014.

[5] I. Kallel, N. Douki, S. Amaidi, and F. Ben Amor, "The incidence of complications of dental trauma and associated factors: a retrospective study," International journal of dentistry, vol. 2020, Article ID 2968174, , 2020.

[6] D. Atabek, A. Alaçam, I. Aydintuğ, and G. Konakoğlu, "A retrospective study of traumatic dental injuries," Dental Traumatology, vol. 30, no. 2, pp. 154-161, 2014.

[7] A. Maguire, J. J. Murray, and I. Al-Majed, "Retrospective study of treatment provided in the primary and secondary care services for children attending a dental hospital following complicated crown fractures in the permanent dentition," International Journal of Paediatric Dentistry, vol. 10, pp. 182-190, 2000.

[8] T. F. R. Lima, J. Y. Nagata, F. J. De Souza-Filho, and A. De Jesus Soares, "Posttraumatic complications of severe luxations and replanted teeth," The Journal of Contemporary Dental Practice, vol. 16, no. 1, pp. 13-19, 2015.

[9] J. O. Andreasen, F. M. Andreasen, A. Skeie, E. HjørtingHansen, and O. Schwartz, "Effect of treatment delay upon pulp and periodontal healing of traumatic dental injuries - a review article," Dental Traumatology, vol. 18, no. 3, pp. 116-128, 2002.

[10] S. Olsburgh, T. Jacoby, and I. Krejci, "Crown fractures in the permanent dentition: pulpal and restorative considerations," Dental Traumatology, vol. 18, no. 3, pp. 103-115, 2002.
[11] S. H. Al-Jundi, "Type of treatment, prognosis, and estimation of time spent to manage dental trauma in late presentation cases at a dental teaching hospital: a longitudinal and retrospective study," Dental Traumatology, vol. 20, no. 1, pp. 1-5, 2004.

[12] T. F. R. Lima, E. J. N. L. D. Silva, B. P. F. D. A. Gomes, J. F. A. D. Almeida, A. A. Zaia, and A. D. J. Soares, "Relationship between initial attendance after dental trauma and development of external inflammatory root resorption," Brazilian Dental Journal, vol. 28, no. 2, pp. 201-205, 2017.

[13] J. E. Enabulele, A. O. Oginni, M. A. Sede, and F. O. Oginni, "Pattern of traumatised anterior teeth among adult Nigerians and complications from late presentation," BMC Research Notes, vol. 9, no. 1, pp. 70-79, 2016.

[14] H. Hecova, V. Tzigkounakis, V. Merglova, and J. Netolicky, “A retrospective study of 889 injured permanent teeth," Dental Traumatology, vol. 26, no. 6, pp. 466-475, 2010.

[15] L. Andersson, "Epidemiology of traumatic dental injuries," Journal of Endodontics, vol. 39, pp. 2-5, 2013.

[16] S. Petti, U. Glendor, and L. Andersson, "World traumatic dental injury prevalence and incidence, a meta-analysis-one billion living people have had traumatic dental injuries," Dental Traumatology, vol. 34, no. 2, pp. 71-86, 2018.

[17] R. Reda, A. Zanza, A. Mazzoni, A. Cicconetti, L. Testarelli, and D. Di Nardo, "An update of the possible applications of magnetic resonance imaging (MRI) in Dentistry: a literature review," Journal of Imaging, vol. 7, no. 5, p. 75, 2021.

[18] C. Wang, M. Qin, and Y. Guan, "Analysis of pulp prognosis in 603 permanent teeth with uncomplicated crown fracture with or without luxation," Dental Traumatology, vol. 30, no. 5, pp. 333-337, 2014.

[19] P. V. Abbott and J. C. Salgado, "Strategies to minimize the consequences of trauma to the teeth," Oral Health and Dental Management, vol. 13, pp. 229-242, 2014.

[20] R. Lam, P. Abbott, C. Lloyd, C. Lloyd, E. Kruger, and M. Tennant, "Dental trauma in an Australian rural centre," Dental Traumatology, vol. 24, no. 6, pp. 663-670, 2008.

[21] S. Lin, N. Pilosof, M. Karawani, R. Wigler, A. Y. Kaufman, and S. T. Teich, "Occurrence and timing of complications following traumatic dental injuries: a retrospective study in a dental trauma department," Journal of clinical and experimental dentistry, vol. 8, pp. e429-36, 2016.

[22] A. J. Moule and C. A. Moule, "The endodontic management of traumatized permanent anterior teeth: a review," Australian Dental Journal, vol. 52, pp. S122-S137, 2007.

[23] N. G. Jackson, P. J. Waterhouse, and A. Maguire, "Factors affecting treatment outcomes following complicated crown fractures managed in primary and secondary care," Dental Traumatology, vol. 22, no. 4, pp. 179-185, 2006.

[24] A. O. Oginni and C. A. Adekoya-Sofowora, "Pulpal sequelae after trauma to anterior teeth among adult Nigerian dental patients," BMC Oral Health, vol. 7, no. 1, p. 11, 2007.

[25] F. C. Yamashita, I. T. S. Previdelli, N. N. O. Pavan, and M. S. Endo, "Retrospective study on sequelae in traumatized permanent teeth," European Journal of Dermatology, vol. 11, no. 03, pp. 275-280, 2017.

[26] F. M. Andreasen and B. Kahler, "Pulpal response after acute dental injury in the permanent dentition: clinical implications-A review," Journal of Endodontics, vol. 41, no. 3, pp. 299-308, 2015.

[27] E. Lauridsen, N. V. Hermann, T. A. Gerds, S. S. Ahrensburg, S. Kreiborg, and J. O. Andreasen, "Combination injuries 1. The risk of pulp necrosis in permanent teeth with concussion injuries and concomitant crown fractures," Dental Traumatology, vol. 28, no. 5, pp. 364-370, 2012. 
[28] E. Lauridsen, N. V. Hermann, T. A. Gerds, S. S. Ahrensburg, S. Kreiborg, and J. O. Andreasen, "Combination injuries 2. The risk of pulp necrosis in permanent teeth with subluxation injuries and concomitant crown fractures," Dental Traumatology, vol. 28, no. 5, pp. 371-378, 2012.

[29] E. Lauridsen, N. V. Hermann, T. A. Gerds, S. S. Ahrensburg, S. Kreiborg, and J. O. Andreasen, "Combination injuries 3. The risk of pulp necrosis in permanent teeth with extrusion or lateral luxation and concomitant crown fractures without pulp exposure," Dental Traumatology, vol. 28, no. 5, pp. 379-385, 2012.

[30] R. Lee, E. J. Barrett, and D. J. Kenny, "Clinical outcomes for permanent incisor luxations in a pediatric population. II. Extrusions," Dental Traumatology, vol. 19, no. 5, pp. 274-279, 2003.

[31] M. Nikoui, D. J. Kenny, and E. J. Barrett, "Clinical outcomes for permanent incisor luxations in a pediatric population. III. Lateral luxations," Dental Traumatology, vol. 19, no. 5, pp. 280-285, 2003.

[32] J. M. Humphrey, D. J. Kenny, and E. J. Barrett, "Clinical outcomes for permanent incisor luxations in a pediatric population. I. Intrusions," Dental Traumatology, vol. 19, no. 5, pp. 266-273, 2003.

[33] J. O. Andreasen, L. K. Bakland, and F. M. Andreasen, "Traumatic intrusion of permanent teeth. Part 2. A clinical study of the effect of preinjury and injury factors, such as sex, age, stage of root development, tooth location, and extent of injury including number of intruded teeth on 140 intruded permanent teeth," Dental Traumatology, vol. 22, no. 2, pp. 90-98, 2006.

[34] K. Bücher, C. Neumann, E. Thiering, R. Hickel, and J. Kühnisch, "Complications and survival rates of teeth after dental trauma over a 5-year period," Clinical Oral Investigations, vol. 17, no. 5, pp. 1311-1318, 2013.

[35] J. V. Bastos and M. I. Côrtes, "Pulp canal obliteration after traumatic injuries in permanent teeth - scientific fact or fiction?" Brazilian Oral Research, vol. 32, p. e75, 2018.

[36] A. Abd-Elmeguid, M. ElSalhy, and D. C. Yu, "Pulp canal obliteration after replantation of avulsed immature teeth: a systematic review," Dental Traumatology, vol. 31, no. 6, pp. 437-441, 2015.

[37] F. A. Amir, J. L. Gutmann, and D. E. Witherspoon, "Calcific metamorphosis: a challenge in endodontic diagnosis and treatment," Quintessence International, vol. 32, pp. 447-455, 2001.

[38] A. F. Queiroz, M. M. Hidalgo, A. Consolaro et al., "Calcific metamorphosis of pulp after extrusive luxation," Dental Traumatology, vol. 35, no. 2, pp. 87-94, 2019.

[39] A. O. Oginni, C. A. Adekoya-Sofowora, and K. A. Kolawole, "Evaluation of radiographs, clinical signs and symptoms associated with pulp canal obliteration: an aid to treatment decision," Dental Traumatology, vol. 25, no. 6, pp. 620-625, 2009.

[40] N. V. Hermann, E. Lauridsen, S. S. Ahrensburg, T. A. Gerds, and J. O. Andreasen, "Periodontal healing complications following concussion and subluxation injuries in the permanent dentition: a longitudinal cohort study," Dental Traumatology, vol. 28, no. 5, pp. 386-393, 2012.

[41] N. V. Hermann, E. Lauridsen, S. S. Ahrensburg, T. A. Gerds, and J. O. Andreasen, "Periodontal healing complications following extrusive and lateral luxation in the permanent dentition: a longitudinal cohort study," Dental Traumatology, vol. 28, no. 5, pp. 394-402, 2012.
[42] A. J. Soares, G. A. Souza, A. C. Pereira, J. Vargas-Neto, A. A. Zaia, and E. J. N. L. Silva, "Frequency of root resorption following trauma to permanent teeth," Journal of Oral Science, vol. 57, no. 2, pp. 73-78, 2015.

[43] B. D. M. De Souza, K. L. Dutra, J. Reyes-Carmona et al., "Incidence of root resorption after concussion, subluxation, lateral luxation, intrusion, and extrusion: a systematic review," Clinical Oral Investigations, vol. 24, no. 3, pp. 1101-1111, 2020.

[44] G. Gambarini, L. Piasecki, G. Miccoli, G. Gaimari, D. D. Nardo, and L. Testarelli, "Cone-beam computed tomography in the assessment of periapical lesions in endodontically treated teeth," European Journal of Dermatology, vol. 12, no. 01, pp. 136-143, 2018.

[45] G. Gambarini, G. Miccoli, M. D’Angelo et al., "The relevance of operative torque and torsional resistance of nickel-titanium rotary instruments: a preliminary clinical investigation," Saudi Endodontic Journal, vol. 10, pp. 260-264, 2020. 